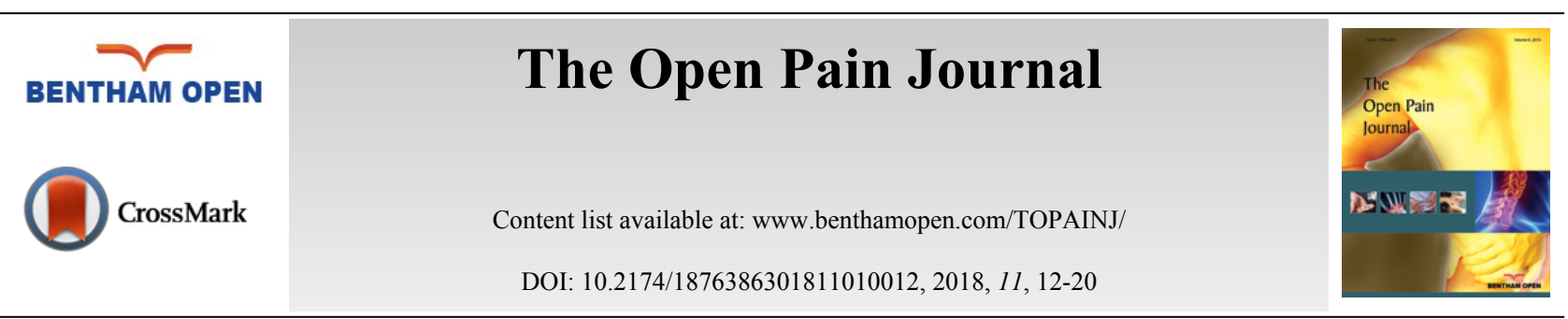

REVIEW ARTICLE

\title{
Dose Can Help to Achieve Effective Pain Relief for Acute Mild to Moderate Pain with Over-the-Counter Paracetamol
}

\author{
Charly Gaul ${ }^{1, * \#}$ and Alain Eschalier, ${ }^{2, \#}$ \\ ${ }^{I}$ Migraine and Headache Clinic Königstein, 61462 Königstein im Taunus, Germany \\ ${ }^{2}$ Université Clermont Auvergne, UMR Inserm Neuro-dol, Institut Analgesia, Clermont-FerrandFrance
}

Received: May 15, 2018

Revised: June 20, 2018

Accepted: July 31, 2018

\begin{abstract}
:
Background:

Paracetamol (acetaminophen) is one of the most widely used Over-The-Counter (OTC) analgesics for the self-treatment of mild to moderate acute pain. Different dosages are used in different countries and, in some of them, a large proportion of adults are using low doses (325 mg to $500 \mathrm{mg}$ ).
\end{abstract}

\section{Objectives:}

The objective of the study was to review information from published research studies to answer the question: is there a dosedependent analgesic effect of paracetamol in the treatment of mild to moderate acute pain?

\section{Methods:}

A detailed assessment of available systematic reviews, meta-analyses and single randomised trials was undertaken based on an electronic literature search focusing on studies comparing higher and lower doses of paracetamol in the management of mild to moderate acute pain.

\section{Results:}

Reviews and comparative trials generally showed greater efficacy with higher dose paracetamol (1000 mg) than with lower doses $(500 \mathrm{mg}$ or $650 \mathrm{mg}$ ) in achieving clinically significant pain relief with comparable tolerability in different types of pain.

\section{Conclusions}

The nature and intensity of the pain are two key elements of the therapeutic choice.

Higher dose immediate-release paracetamol (1000 mg), used for a short duration of time (4-5 days) and adhering to recommendations within the label for risk groups, delivers safe and more effective analgesia than lower doses for adults with mild to moderate acute pain.

\section{Strengths and Limitations of this Study:}

- Paracetamol is one of the most widely used OTC analgesics for the self- treatment of mild to moderate acute pain and this study aims to explore the practical question of whether the use of low doses, which is common in some countries, provides suboptimal pain relief.

- This review provides an overview of previous studies focusing on comparing the analgesic efficacy of different doses of paracetamol rather than comparing the effect of different OTC analgesics.

* Address correspondence to this author at the Charly Gaul Ölmühlweg 31, 61462 Königstein im Taunus, Germany, Tel: +49 (0) 6174-29040, Fax:+49 (0) 6174-2904100, E-mail: c.gaul@migraene-klinik.de

"Both authors contributed equally to this work. 
- This review details a narrative assessment of available systematic reviews, meta-analysis and randomised trials but does not offer a quantitative analysis of pain relief achieved with different doses of paracetamol.

- The review does not provide an overview of studies focusing on different forms of paracetamol.

- The focus for this review is immediate release paracetamol. Combined and slow release paracetamol formulations were not considered of relevance. The latter are in the process of being suspended across the European Union due to safety concerns with overdosing [1].

Keywords: Paracetamol, OTC, Pain, Doses, Review, Clinical trials.

\section{BACKGROUND}

Paracetamol is one of the most commonly used Over-The-Counter (OTC) analgesics in the self-treatment of acute mild to moderate pain [2]. Paracetamol is a non-opioid, centrally acting analgesic, available in a wide range of OTC preparations, at different doses and in a variety of formulations and combinations. Paracetamol is typically made available at two doses: $325 \mathrm{mg}$ and $500 \mathrm{mg}$ formulations, with the usual oral dose for adults being $0.5 \mathrm{~g}$ to $1 \mathrm{~g}$ every four to six hours up to a maximum of $4 \mathrm{~g}$ daily [3-5].

A systematic review of patients' views has shown that pain sufferers want to achieve either a substantial reduction in their pain intensity of $50 \%$ or more, or to achieve a low pain state, with no worse than mild pain [6]. They also want substantial improvement in the impaired quality of life, fatigue and distress that are generally associated with being in pain [6]. Choosing an effective analgesic is essential to achieving adequate pain relief for the immediate symptoms of acute pain. Further, it has been shown that reducing pain has wider benefits. For example, a recent study in migraineurs showed more than a doubling in risk of new-onset chronic migraine over one year in patients who self-reported poor treatment efficacy compared to those who achieved maximum efficacy from their treatment (odds ratio 2.55) [7]. Good efficacy and rapid onset of pain relief can also reduce the risk of excessive dosing with an analgesic [8].

At recommended doses, paracetamol has been shown to be clinically effective in relieving mild to moderate pain due to a wide range of common causes, including tension-type headache [9], migraine [10], pain after oral surgery (such as simple tooth extraction, periodontal surgery and surgical removal of third molars), and pain after tonsillectomy [4]. The balance of paracetamol's efficacy and tolerability means that it is recommended as a first-line choice in evidencebased guidelines for several conditions causing mild to moderate pain, such as the recommendation for tension- type headache use in the British Association for the Study of Headache (BASH) guidelines [11]. Guidelines from the German, Austrian and Swiss Headache Societies and the German Society of Neurology recommend paracetamol as a first-line option for self-medication of migraine attacks and the fixed-dose combination of paracetamol, aspirin and caffeine and the combination of paracetamol and caffeine as first-line therapies for tension-type headache [12].

Osteoarthritis Research Society International (OARSI) guidelines recommend the use of paracetamol (up to $4 \mathrm{~g} / \mathrm{day}$ ) as an effective initial oral analgesic for the treatment of mild to moderate pain in patients with knee or hip osteoarthritis [13]. For osteoarthritis of the hand, the European League Against Rheumatism (EULAR) guidelines recommend paracetamol (up to $4 \mathrm{~g}$ /day) as the oral analgesic of the first choice because of its efficacy and safety [14].

However, there are concerns that in some countries, such as Germany, a large proportion of adults take doses of non-prescription paracetamol that are lower than recommended to achieve adequate relief of pain. A recent survey of 2000 adults aged 18 to 75 years who purchased an oral analgesic from a pharmacy in Germany over the previous six months showed that $91 \%$ of people thought they were taking the correct dosage to treat headache. However, the majority (71\% of users) used a single $500 \mathrm{mg}$ paracetamol tablet [15].

Recent sales figures for non-prescription paracetamol for pain relief in adults showed wide variations between different countries in the formulation strength purchased Table 1. More than three-quarters (76\%) of OTC paracetamol purchased in France and more than half (59\%) in Spain was at the 1000mg unit dose, compared to only 3\% in Germany, where the vast majority of sales (97\%) were for the 500mg unit dose [16].

Does the widespread use of lower dose paracetamol in some countries potentially reduce the pain relief that people experience? Studies in experimental models of human pain and common consumer experience have shown a clear doseresponse for the analgesic effect with paracetamol [17 - 20], however, there has been a limited analysis of the clinical efficacy of different doses of paracetamol in the 'real life' clinical management of mild to moderate acute pain. 
Table 1. OTC paracetamol sales at different doses for pain relief in adults [16].

\begin{tabular}{|c|c|c|c|c|c|c|c|}
\hline $\begin{array}{l}\text { Paracetamol unit doseused for Adults Pain } \\
\text { Relief (OTC only) - volume split (\% units) }\end{array}$ & France & Germany & Italy & Poland & Spain & Russia & Portugal \\
\hline $1000 \mathrm{mg}$ & $76 \%$ & $3 \%$ & NA & NA & $59 \%$ & NA & NA \\
\hline $500 \mathrm{mg}$ & $24 \%$ & $97 \%$ & $97 \%$ & $99 \%$ & $20 \%$ & $98 \%$ & $95 \%$ \\
\hline
\end{tabular}

(NA - not applicable because the product is prescription only)

\section{METHODOLOGY}

We carried out a focused review of published research studies comparing high dose (1000 mg) paracetamol with lower doses $(500 \mathrm{mg}$ or $650 \mathrm{mg}$ ) in acute pain and reporting on the efficacy of analgesia to answer the research question: what is the clinical efficacy of $1000 \mathrm{mg}$ paracetamol compared to lower doses (500 $\mathrm{mg}, 650 \mathrm{mg})$ for the treatment of pain (Fig. 1) Search terms used in the electronic PubMed literature review were:

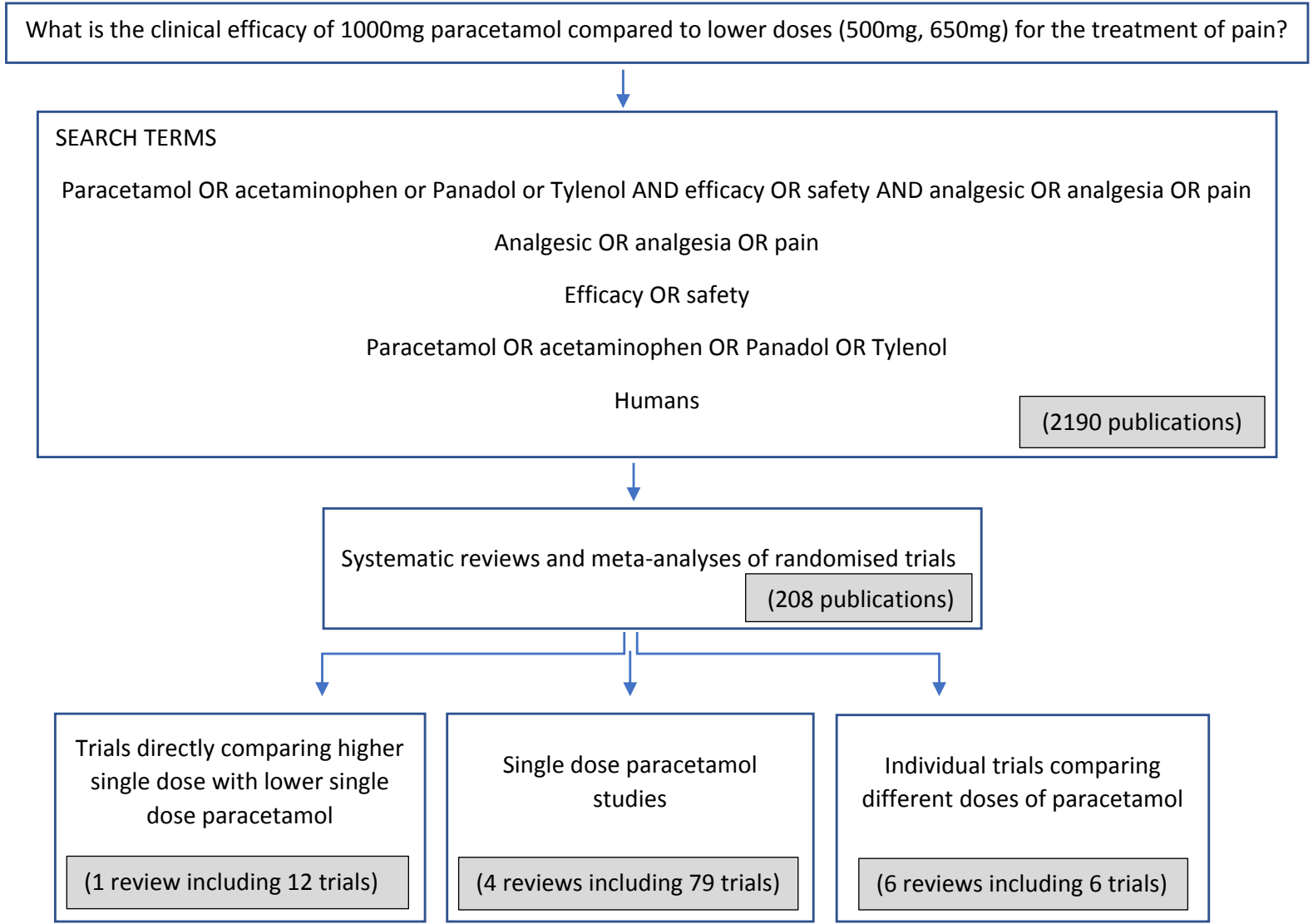

Fig. (1). Methodology - selection process for the clinical studies included in this review.

- Paracetamol OR acetaminophen or Panadol or Tylenol AND efficacy OR safety AND analgesic OR analgesia OR pain

- Analgesic OR analgesia OR pain

- Efficacy OR safety

- Paracetamol OR acetaminophen OR Panadol OR Tylenol

- Humans

Systematic reviews and meta-analyses of randomised trials provide the highest level of research evidence for an intervention so we focused primarily on these before looking briefly at single trials to gain a broader view of the efficacy of pain relief achieved with paracetamol. First, we looked at systematic reviews and meta- analyses of trials making direct comparisons of two or more different doses of paracetamol in the same study. Second, we considered 
systematic reviews comparing different doses of paracetamol indirectly by including trials that each assessed the analgesic efficacy of only one dose of paracetamol. Third, we reviewed randomised trials not included in previous systematic reviews that compared two different doses of paracetamol directly within each trial. Data from modified release formulations of paracetamol were not included. Of the trials ultimately included in this review, none utilised effervescent paracetamol formulations.

\section{RESULTS}

\subsection{Trials Directly Comparing Higher Single Dose with Lower Single Dose Paracetamol}

A large systematic review of randomised, double-blind trials directly comparing different doses of paracetamol in the management of acute mild to moderate pain published in 2006 found that a higher dose of paracetamol (1000mg) was statistically superior to lower dose paracetamol (500mg) in analgesic effect [19].

The study authors searched the published literature systematically for randomised, double-blind clinical trials comparing at least two doses of paracetamol with placebo or an active comparator in pain including a minimum of 10 patients in each treatment group. They carried out two levels of analysis: first taking a broad approach to which trials they included, looking at trials reporting results on pain intensity or pain relief over a four to six hour period and second including only those trials carried out in patients with initial pain that was at least moderate in intensity and that included at least 10 patients in each treatment arm.

The meta-analysis identified nine study citations of 12 trials directly comparing more than one dose of paracetamol in single-dose studies. Results showed that for the nine studies comparing 500mg with 1000mg doses of paracetamol, eight showed greater efficacy on a numerical basis with the higher dose. In addition, nine of the 12 studies overall demonstrated numerically greater analgesic efficacy with the higher dose of paracetamol [19].

Results from the second level of analysis, including seven studies in pain of at least moderate intensity, showed that pain relief of at least $50 \%$ occurred more frequently with higher dose paracetamol (1000mg) than with lower dose $(500 \mathrm{mg})$. Nearly two- thirds $(64 \%)$ of patients achieved analgesia of this magnitude compared to just over half (52\%) with the lower dose, based on the pooled data. The relative benefit with higher dose (1000mg) paracetamol compared to lower dose $(500 \mathrm{mg})$ was $1.2(95 \%$ CI $1.1,1.4)$. The number needed to treat (NNT) for one additional patient to obtain pain relief of at least $50 \%$ at the higher dose of paracetamol compared to the lower dose was 9 (95\% CI 6,20). In the same analysis, the NNT for aspirin $(500,600 \mathrm{mg}$ vs $1000,1200 \mathrm{mg})$ was $16(95 \% \mathrm{CI} 8,>100)$ and for ibuprofen (200 $\mathrm{mg}$ vs $400 \mathrm{mg})$ the NNT was 10 (95\% CI 6, 23) [19].

The review authors suggested that the practical implication of their findings was that a higher dose of paracetamol delivers adequate analgesia for more patients than a lower dose, where this is a safe option [19].

\subsection{Single Dose Paracetamol Studies}

A recent Cochrane review included an assessment of trials that included single oral doses of paracetamol for treating acute painful conditions in adults as part of a broader review of OTC analgesics. A dose-response effect was less clear [20]. However, it has been suggested that dose-response may be more successfully assessed using trials directly comparing two doses [21], as evidenced in a recent review [19].

The Cochrane overview found that the success rate for analgesia was greater with higher dose paracetamol $(975 / 1000 \mathrm{mg})$ at $34 \%$ than with lower doses $(600 / 650 \mathrm{mg})$ at $26 \%$, but an even higher success rate was seen with a $500 \mathrm{mg}$ dose $(43 \%)$ [20]. The success rate was calculated as the proportion of study participants achieving good pain relief with analgesic minus the proportion gaining good relief with placebo, and expressing this as a percentage of the maximum possible success rate for the analgesic (i.e. 100 minus the response rate with placebo). Further findings showed that the NNT for at least 50\% maximum pain relief over four to six hours was lower for higher dose $(975 / 1000 \mathrm{mg})$ paracetamol at $3.6(95 \%$ confidence interval 3.2 to 4.1$)$ than for lower dose $(600 / 650 \mathrm{mg})$ paracetamol, where the NNT was 4.6 (3.9 to 5.5). The NNT was lower (3.5) for 500mg paracetamol (2.7 to 4.8) [20].

Similar findings, with no clear dose-response relationship for NNT after low and high doses of paracetamol, came from a Cochrane review of single dose paracetamol trials in postoperative pain [22], while a review of data by the US Food and Drug Administration (FDA) [23, 24] gave an NNT of 3.7 for 1000mg paracetamol and 5.4 for lower doses of $600 / 650 \mathrm{mg}$ paracetamol. A Cochrane review of randomised trials of paracetamol in acute treatment of frequent episodic tension-type headache in adults showed greater pain relief with higher dose paracetamol. The NNT with paracetamol 
$1000 \mathrm{mg}$ was 10 (7.9 to 14) for being pain-free or mild pain at two hours after taking treatment compared with placebo [25]. Limited data showed that the efficacy of paracetamol $500 \mathrm{mg}$ to $650 \mathrm{mg}$ was not superior to placebo [25].

\subsection{A closer look at individual Trials Comparing Different Doses of Paracetamol}

The next level of evidence is single double-blind randomised trials. Many studies have evaluated the effectiveness of paracetamol at doses of either $1000 \mathrm{mg}$ or lower doses such as $650 \mathrm{mg}$ or $500 \mathrm{mg}$ but relatively few have compared the two doses within the same trial. In this section, we will take a closer look at randomised trials, not included in previous reviews, which have compared higher dose with lower dose paracetamol in the same study.

Two single-dose randomised studies comparing different doses of a Fast-Dissolving Paracetamol (FD-APAP) tablet in postsurgical dental pain showed that patients taking higher dose paracetamol $(1000 \mathrm{mg})$ had significantly better pain relief over the five hours after the dose compared to those randomised to lower doses of either 500mg or 650mg [8] (Fig. 2). Higher dose paracetamol achieved significantly superior pain relief $(p<0.05)$, faster onset and longer duration of pain relief compared with $500 \mathrm{mg}$ or $650 \mathrm{mg}$ doses. Onset of confirmed first perceptible pain relief occurred at 15 minutes after taking the $1000 \mathrm{mg}$ dose, which was $32 \%$ shorter than with the $500 \mathrm{mg}$ dose $(22$ minutes; $p=0.047)$ [8]. Mean duration of pain relief was approximately five-six hours with the 1000mg dose compared to two-three hours with $500 \mathrm{mg}[8]$.

Further, a study in post-surgical dental pain showed that paracetamol 1000mg provided clinically meaningful and statistically greater efficacy compared with paracetamol $650 \mathrm{mg}$ and placebo [26]. This study in post-surgical dental pain was considered, together with the two systematic reviews [19-20] mentioned previously, by the Canadian Agency for Drugs and Technologies in Health in a recent report looking at single-dose trials comparing 1000mg oral paracetamol with $600 / 650 \mathrm{mg}$ oral paracetamol in adults experiencing pain [5]. The Agency concluded that the findings were consistent with evidence reviewed by the US FDA, showing that 1000mg single dose paracetamol was more effective than $650 \mathrm{mg}$ single dose in various pain conditions [23, 24]. The authors of the Canadian Agency report noted that the FDA report had encouraged the use of the lowest effective dose and suggested reducing the maximum single dose from $1000 \mathrm{mg}$ to $650 \mathrm{mg}$, but they pointed out that the rationale for this recommendation was not provided. They added that comparative studies on the currently recommended maximum daily dose (4g) and long-term use of paracetamol are needed [5].

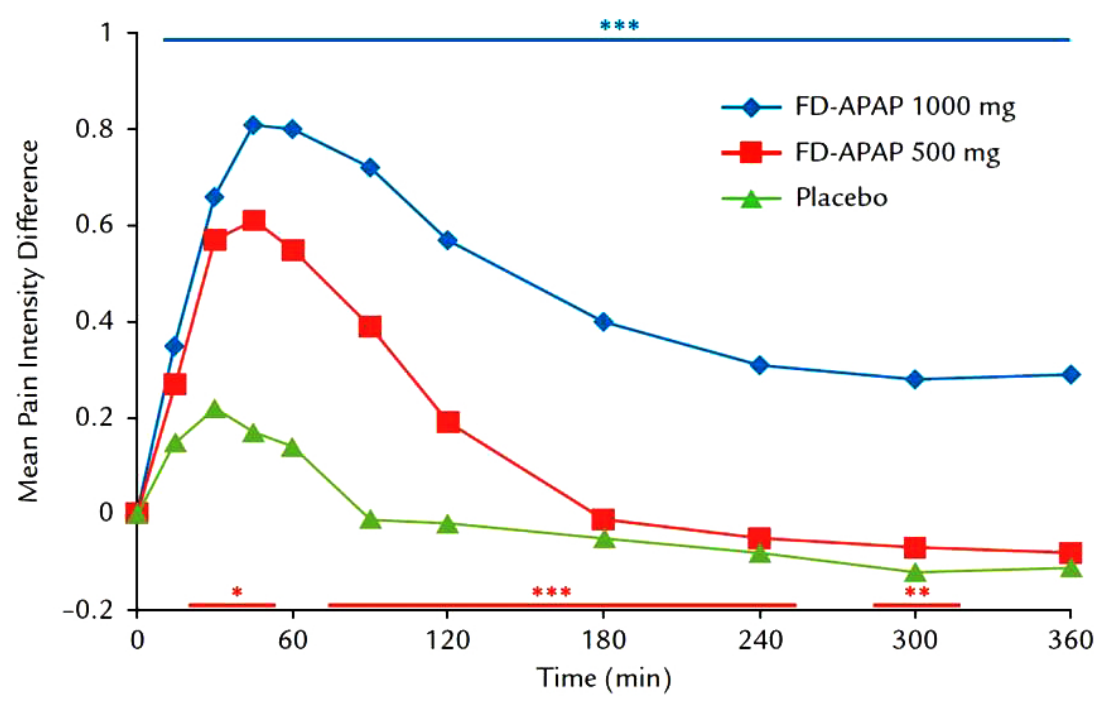

$$
\begin{aligned}
& \text { Key: * FD-APAP } 1000 \mathrm{mg} \text { vs } 500 \mathrm{mg} \mathrm{p}<0.05 ;{ }^{* *} \text { FD-APAP } 1000 \mathrm{mg} \text { vs } 500 \mathrm{mg} \mathrm{p}=0.01 \text {; } \\
& * * * \text { FD-APAP } 1000 \mathrm{mg} \text { vs } 500 \mathrm{mg} \mathrm{p} \leq 0.009 ; * * * \text { FD-APAP } 1000 \mathrm{mg} \text { vs placebo } \mathrm{p}<0.008 \\
& \text { (reprinted with permission from Elsevier HS Journals Inc) }
\end{aligned}
$$

Fig. (2). Mean pain intensity difference from 15 minutes to six hours for patients undergoing surgical removal of impacted molar [8]. 


\subsection{Safety of Higher Dose vs Lower Dose Paracetamol for Short-term Acute Pain Management}

Together with efficacy in achieving pain relief, safety is an essential factor to consider in the use of self-medication with non-prescription analgesics. Safety concerns previously reported with paracetamol have generally occurred in people with specific risk factors or have been associated with high-dose and long-duration treatment and exceeding the recommended maximum daily dose [27 - 30].

The previously mentioned Cochrane review of non-prescription oral analgesics for acute pain reported safety data for paracetamol 975/1000mg and for paracetamol 600/650mg [20]. The data showed that the risk of having adverse events was similar between the two doses of paracetamol: $18 \%$ of patients taking paracetamol $975 / 1000 \mathrm{mg}$ had at least one adverse event (headache, nausea or dizziness) compared to $16 \%$ of those taking $600 / 650 \mathrm{mg}$ [20]. These high rates are sequalae of the dental surgical model used in the studies reviewed by Cochrane. When treatment- related adverse events are compared for higher single dose paracetamol (1000mg), lower single dose paracetamol (650mg) and placebo in the treatment of postsurgical dental pain, low rates are seen with events reported by $0.8 \%$ and $1.2 \%$ of patients, for high and low doses respectively [26]. There were no clinically important differences among the different treatment groups. No serious adverse events were reported and no patients discontinued the study due to an adverse event [26].

Hepatotoxicity is a well-established consequence of paracetamol overdose. However, the risk of clinically significant hepatotoxicity at therapeutic doses of paracetamol is very low in patients [31, 32]. A recent review tried to identify specific phenotypes and genotypes in patients, such as age, body weight, genetic information or diet, that could make them particularly susceptible to paracetamol hepatotoxicity [33]. The authors concluded that there is no group of patients that represents a higher risk of paracetamol-induced hepatotoxicity [33]. In addition, a recent article reported possible impacts on the infants following paracetamol use during pregnancy [34]. Although not yet conclusive, these data suggest, in our view, as with all medicines in pregnancy, care should be taken and as a precaution, paracetamol should not be used without medical advice during pregnancy.

\section{DISCUSSION}

This focused narrative review of available systematic reviews, meta-analyses and single randomised controlled trials showed that higher single dose paracetamol $(1000 \mathrm{mg})$ generally achieves more effective pain relief than low single dose paracetamol (500mg or $650 \mathrm{mg}$ ). The greater pain relief was most clearly shown in studies directly comparing the two doses of paracetamol. The rate of adverse events was similar in studies comparing higher dose with lower dose paracetamol.

The findings suggest that health professionals, both physicians and pharmacists, could recommend a higher dose of paracetamol (1000mg) for acute pain in adult patients, for a short duration of time (4-5 days), either immediately or if the patient has previously taken a lower dose $(500 \mathrm{mg} / 650 \mathrm{mg})$ that has proven to be ineffective, providing they do not have risk factors for adverse events with paracetamol. If patients do not gain sufficient pain relief with higher dose paracetamol, they could be advised to try a different analgesic drug.

Several studies report adverse or toxic effects of paracetamol, we mention above the risk of hepatoxicity and recommend caution in subjects at risk of adverse effects or in special situations.

\section{CONCLUSION}

These findings have important implications for health professionals advising patients on the optimal dose of nonprescription immediate-release paracetamol to achieve effective pain relief. Although paracetamol should always be used in accordance with its label, with special regard to the recommendations for patients at risk for side-effects and during pregnancy, higher dose paracetamol can be used (immediately or in a dose escalation strategy), for a short duration of time, to achieve more effective analgesia than lower dose paracetamol for adults with acute, mild to moderate pain and no increased risk of side-effects. However, as noted by Moore et al. [35] we must keep in mind that just because a higher dose of a particular analgesic achieves more effective pain relief in a larger proportion of people than a lower dose, that does not necessarily apply to everyone because of individual variations. It is important to tailor analgesics to the needs and experience of the individual.

\section{CONSENT FOR PUBLICATION}

Not applicable. 


\section{FUNDING}

This work was supported in full by PGT Healthcare LLP. All attributed authors participated in the development and review of this manuscript.

\section{CONFLICT OF INTEREST}

Charly Gaul has received honoraria for giving talks or consulting from: Allergan Pharma, Boehringer Ingelheim Pharma, Lilly, Novartis Pharma, Desitin Arzneimittel, Cerbotec, Bayer vital, Hormosan Pharma, electroCore und Grünenthal, Reckitt Benckiser, PGT Healthcare. He does not hold any stocks in pharmaceutical companies.

Alain Eschalier has received honoraria (transferred to the benefit of the Institut Analgesia) for giving talks or consulting from: Grünenthal, Kyowa Kirin, Innopain, Menarini, PGT Healthcare, Unither, UPSA. He does not hold any stocks in pharmaceutical companies. I now add UPSA.

\section{ACKNOWLEDGEMENTS}

Thanks to Susan Mayor PhD for editorial support.

\section{REFERENCES}

[1] European Medicines Agency. Modified-release paracetamol-containing products to be suspended from EU market 2017.

[2] Dale O, Borchgrevink PC, Fredheim OM, Mahic M, Romundstad P, Skurtveit S. Prevalence of use of non-prescription analgesics in the Norwegian HUNT3 population: Impact of gender, age, exercise and prescription of opioids. BMC Public Health 2015 ; $15(1)$ : 461. [http://dx.doi.org/10.1186/s12889-015-1774-6] [PMID: 25934132]

[3] Parfitt K, Martindale W. Martindale: The complete drug reference. London, UK: Pharmaceutical Press 1999.

[4] McNeil Consumer Healthcare. Tylenol Professional Product Information. 2010

[5] Canadian Agency for Drugs and Technologies in Health. Rapid Response Report: Summary with Critical Appraisal. 1000mg versus 600/650mg acetaminophen for pain or fever: A review of the clinical efficacy Available from: 2013. https://www.cadth.ca/sites/ default/files/pdf/htis/ june2016/RC0786\%20Acetaminop hen\%20Dose\%20Final.pdf 17 June 2016.

[6] Moore RA, Straube S, Aldington D. Pain measures and cut-offs - 'no worse than mild pain' as a simple, universal outcome. Anaesthesia 2013; 68(4): 400-12.

[http://dx.doi.org/10.1111/anae.12148] [PMID: 23347230]

[7] Lipton RB, Fanning KM, Serrano D, Reed ML, Cady R, Buse DC. Ineffective acute treatment of episodic migraine is associated with newonset chronic migraine. Neurology 2015; 84(7): 688-95.

[http://dx.doi.org/10.1212/WNL.0000000000001256] [PMID: 25609757]

[8] Yue Y, Collaku A, Brown J, et al. Efficacy and speed of onset of pain relief of fast-dissolving paracetamol on postsurgical dental pain: Two randomized, single-dose, double-blind, placebo-controlled clinical studies. Clin Ther 2013; 35(9): 1306-20.

[http://dx.doi.org/10.1016/j.clinthera.2013.07.422] [PMID: 23972577]

[9] Steiner TJ, Lange R, Voelker M. Aspirin in episodic tension-type headache: Placebo-controlled dose-ranging comparison with paracetamol. Cephalalgia 2003; 23(1): 59-66. [http://dx.doi.org/10.1046/j.1468-2982.2003.00470.x] [PMID: 12534583]

[10] Lipton RB, Baggish JS, Stewart WF, Codispoti JR, Fu M. Efficacy and safety of acetaminophen in the treatment of migraine: Results of a randomized, double-blind, placebo-controlled, population-based study. Arch Intern Med 2000; 160(22): 3486-92. [http://dx.doi.org/10.1001/archinte.160.22.3486] [PMID: 11112243]

[11] British Association for the Study of Headache. British Association for the Study of Headache. Guidelines for all healthcare professionals in the diagnosis and management of migraine, tension-type headache, cluster headache, medication-overuse headache [Internet] Hull, UK: British Association for the Study of Headache 2010 [cited 2017 Jul 04] Available from: wwwbashorguk 2010.www.bash.org.uk

[12] Haag G, Diener HC, May A, et al. Self-medication of migraine and tension-type headache: Summary of the evidence- based recommendations of the Deutsche Migräne und Kopfschmerzgesellschaft (DMKG), the Deutsche Gesellschaft für Neurologie (DGN), the Österreichische Kopfschmerzgesellschaft (ÖKSG) and the Schweizerische Kopfwehgesellschaft (SKG). J Headache Pain 2011; 12(2): 201-17.

[http://dx.doi.org/10.1007/s10194-010-0266-4] [PMID: 21181425]

[13] Zhang W, Moskowitz RW, Nuki G, et al. OARSI recommendations for the management of hip and knee osteoarthritis, Part II: OARSI evidence-based, expert consensus guidelines. Osteoarthritis and cartilage 2008; 16(2): 137-62.

[http://dx.doi.org/10.1136/ard.2006.062091] [PMID: 17046965] 
[14] Zhang W, Doherty M, Leeb BF, et al. EULAR evidence based recommendations for the management of hand osteoarthritis: report of a Task Force of the EULAR Standing Committee for International Clinical Studies Including Therapeutics (ESCISIT). Annals of the rheumatic diseases 2007; 66(3): 377-88.

[http://dx.doi.org/10.1136/ard.2006.062091] [PMID: 17046965]

[15] PGT Healthcare. Data on file. 2017

[16] PGT Healthcare. Data on file. 2017. Data source: IMS PADDS 2016

[17] Piguet V, Desmeules J, Dayer P. Lack of acetaminophen ceiling effect on R-III nociceptive flexion reflex. Eur J Clin Pharmacol 1998; 53(5): $321-4$. [http://dx.doi.org/10.1007/s002280050386] [PMID: 9516030]

[18] Yuan CS, Karrison T, Wu JA, Lowell TK, Lynch JP, Foss JF. Dose-related effects of oral acetaminophen on cold-induced pain: A doubleblind, randomized, placebo- controlled trial. Clinical Pharmacology \& Therapeutics 1998; 1;63(3): 379-83.

[19] McQuay HJ, Moore RA. Dose-response in direct comparisons of different doses of aspirin, ibuprofen and paracetamol (acetaminophen) in analgesic studies. Br J Clin Pharmacol 2007; 63(3): 271-8.

[PMID: 16869819]

[20] Moore RA, Wiffen PJ, Derry S, Maguire T, Roy YM, Tyrrell L. Non-prescription (OTC) oral analgesics for acute pain-an overview of Cochrane reviews. Cochrane Database Syst Rev 2013; 10. [PMID: 26544675]

[21] Toms L, McQuay HJ, Derry S, Moore RA. Single dose oral paracetamol (acetaminophen) for postoperative pain in adults. Cochrane Database Syst Rev 2008; 4: CD004602. [PMID: 18843665]

[22] Barden J, Edwards J, Moore A, McQuay H. Single dose oral paracetamol (acetaminophen) for postoperative pain. Cochrane Database Syst Rev 2004; 1: CD004602.

[PMID: 14974073]

[23] Kuffner E, Gelotte C, Rothman K. Consumer Healthcare.. Acetaminophen containing medicines [Internet]. Silver Spring (MD): US Food and Drug Administration (Presented at the joint Meeting of the Drug Safety and Risk Management Advisory Committee, Nonprescription Drugs Advisory Committee and the Anesthetic and Life Support Drugs Advisory Committee Available from: 2009.http://www.fda.gov/downloads/AdvisoryCommittees/CommitteesMeetingMaterials/ Drugs/DrugSafetyandRiskManagementAdvisoryCommittee/ UCM171571.pdf cited 2016 May 19

[24] McNeil C, Pharmaceuticals S. McNeil's background package on acetaminophen for the September 19, 2002 Nonprescription Drugs Advisory Committee meeting. Silver Spring, MD: U.S. Food and Drug Administration 2002.http://www.fda.gov/ohrms/dockets/ac/02/ briefing/3882B1_13_McNeil-Acetaminophen.htm [cited 2016 May 19]

[25] Stephens G, Derry S, Moore RA. Paracetamol (acetaminophen) for acute treatment of episodic tension-type headache in adults. Cochrane Database Syst Rev 2016; 6: CD011889. [PMID: 27306653]

[26] Qi DS, May LG, Zimmerman B, et al. A randomized, double-blind, placebo-controlled study of acetaminophen 1000 mg versus acetaminophen $650 \mathrm{mg}$ for the treatment of postsurgical dental pain. Clin Ther 2012; 34(12): 2247-2258.e3. [http://dx.doi.org/10.1016/j.clinthera.2012.11.003] [PMID: 23200183]

[27] Yoon E, Babar A, Choudhary M, Kutner M, Pyrsopoulos N. Acetaminophen- induced hepatotoxicity: A comprehensive update. J Clin Transl Hepatol 2016; 4(2): 131-42. [PMID: 27350943]

[28] Roberts E, Nunes VD, Buckner S, et al. Paracetamol: Not as safe as we thought? A systematic literature review of observational studies. Ann Rheum Dis 2016; 75(3): 552-9.

[29] Schwarz ES, Delgado Nunes Mullins ME. Paracetamol: Is all the concern valid?. Ann Rheum Dis 2015; 75(3): 552-9. [http://dx.doi.org/10.1136/annrheumdis-2015-206914] [PMID: 25732175]

[30] Roberts E, Conaghan PG. Response to:'Paracetamol: Is all the concern valid?' by Schwarz and Mullins. Annals of the rheumatic diseases 2015. Apr 28:annrheumdis- 2015.

[31] Watkins PB, Kaplowitz N, Slattery JT, Colonese CR, Colucci SV, Stewart PW. Aminotransferase elevations in healthy adults receiving 4 grams of acetaminophen daily: A randomized controlled trial. Jama 2006; 296(1): 87-93. [http://dx.doi.org/10.1001/jama.296.1.87] [PMID: 16820551]

[32] Heard K, Green JL, Anderson V, Bucher-Bartelson B, Dart RC. A randomized, placebo-controlled trial to determine the course of aminotransferase elevation during prolonged acetaminophen administration. BMC Pharmacol Toxicol 2014; $15(1): 39$. [http://dx.doi.org/10.1186/2050-6511-15-39] [PMID: 25047090]

[33] Caparrotta TM, Antoine DJ, Dear JW. paracetamol-induced liver injury? A critical review of the literature. Eur J Clin Pharmacol 2017; 1-4. [PMID: 29067481]

[34] Bornehag CG, Reichenberg A, Hallerback MU, et al. Prenatal exposure to acetaminophen and children's language development at 30 months. Eur Psychiatry 2018. 
[35] Moore RA, Derry S, Wiffen PJ, Straube S, Aldington DJ. Overview review: Comparative efficacy of oral ibuprofen and paracetamol (acetaminophen) across acute and chronic pain conditions. Eur J Pain 2015; 19(9): 1213-23.

[http://dx.doi.org/10.1002/ejp.649] [PMID: 25530283]

\section{(C) 2018 Gaul and Eschalier.}

This is an open access article distributed under the terms of the Creative Commons Attribution 4.0 International Public License (CC-BY 4.0), a copy of which is available at: (https://creativecommons.org/licenses/by/4.0/legalcode). This license permits unrestricted use, distribution, and reproduction in any medium, provided the original author and source are credited. 